this and over the chest to the fractured clavicle. The third bandage of Desault forms two triangles; one is in front and the other is behind the chest. It is quite complicated, and liable to become disarranged unless pimed at every crossing. Another favorite dressing, and one that is very effective, is that of Dr. A. Sayres, of New York. It consists of adhesive plaster 3 inches wide. One strip is applied by forming a loop around the arm of the affected side, well up the axilla; then, having the arm in position, draw the strip around the body over the back, draw it tightly and secure it to the chest, thus drawing the outer fragment outwards. A second strip is placed under the elbow and both ends fastened over the opposite shoulder drawing it backwards, at the same time supporting the forearm. When there is difficulty in holding the fragments in apposition there is no method so effective as this, except the position on the back.

\section{ABSCESS OF THE THIGH.}

This man sustained a fracture of the femur two years ago. Some time after its union, an abscess occurred at the place of fracture, and some pieces of bone came out, going to show that there was some disease of the bone. By measuring, I find the injured limb $1 \frac{3}{4}$ inch shorter than the other. I see scars where abscesses have been. At present the outer and posterior surface has the appearance of an abscess. I propose to open this and examine the bone with a probe, and if any diseased bone or loose pieces of bone are present, I will remove them. I will open the abscess first, making a free incision. I suppose there is tubercular matter in this, and upon a microscopical examination we might find the bacilli of tuberculosis. There is a cloaca here, and when they are present, they generally lead down to diseased bone. I pass a probe and find a roughened condition of the bone, but not diseased portions. I will put in a drainage tube through the $\lim b$, and thus hope to cure the sinuses.

This is what is called through drainage, and it is employed in compound fractures. It will be thoroughly washed out with antiseptic fluid, also scraped out with a Volkmann's spoon. The large incision on the outer side of the leg will be partly sewed up with catgut sutures. It will be put up in the usual antiseptic dressings, and I will direct that it be washed ont every day, and we thus hope to effect a cure.

$$
\text { Norember 29, } 1890 .
$$

Gentlemen: I propose to make some remarks about fractures, as that is the subject I am lecturing on now. Fractures of the femur may be divided into three classes, viz.: 1, those of the upper extremity may be subdivided into intra-capsular and extra-capsular. This was the classification of Sir Astley Cooper, and it is a very good one. A fracture within the capsular ligament is usually considered by surgeons as one that does not unite. There may be some rare exceptions. The causes of non-union of intra-capsular fractures are on account of the deficient vascular supply to the fragment, the difficulty in keeping the fragments in apposition, and the presence of the synovial fluid at seat of fracture.

Fracture of the neck of the femur occurs usually in old people, 60 years or more of age, and most fre. quently in women. The cause of fractures being more frequent in old persons is usually said to be an excess of earthy matter in the bones. This theory is now about abandoned, because on examination of the bones of old persons it is found that the compact substance has become thinner than normal, and the cells in the spongy substance larger, hence there is really less bone, and consequently more fragile. In old people a very trivial cause may produce a fracture, such as slipping from a curbstone, tripping over a loose piece of carpet, an unexpected step, or even turning in bed. We are never able to tell exactly whether a fracture is intra-capsular or not. Extracapsular fracture of the neck of the femur occurs more frequently in younger persons, caused by falls on the trochanter or other direct violence. This form of fracture unites well, the amount of callus being very large. The shortening in these cases of intracapsular fracture, determined by measurement from the anterior superior spinous processes to the inner malleoli, is usually small at first (about $\frac{1}{2}$ inch), and subsequently increased to $1 \frac{1}{2}$ or 2 inches, by the giving way of the ligaments and the capsule. When this gradual shortening takes place, you may be certain that it is intra-capsular. In extra-capsular fracture, the shortening is as much at first as afterwards. Both these varieties may be impacted fractures, the neck being driven into the head or into the spongy portion of the trochanter major.

It is very important that you do not break up the impaction by your manipulation, because the union would not take place near so readily, or probably never.

( To be Continued.)

\section{CASES TREATED BY METHYI,VIOLET.}

Reported to the Kansas City Acalemy of Medicine, January 2, 1892. BY FI,AVET, B. TIFFANY, M.D., PROFESSOR OF OPHTHALMOLOGY, TNIYFRSITY MEDYCAL COLLEGE, KANSAS

Case 1.-Phlyctenular keratitis or papillary cornetis as treated by methyl-violet. Dosia Huston, age 5 years, was brought for treatment December 11 , 1891. History as obtained from the father: "Child has had very sore eyes for over a year; has not been able to open her eyes nor bear any light for several months. Her face has been sore and covered with scabs for a long time. The eyes constantly water, and tears seem to scald the face. She never wants to go in the light, but begs always to stay in the house where it is dark; she lies much of the time with her face on the floor with her sumbonnet on, or face buried in a pillow or on her mother's lap. If up, she goes with hands over the eyes."

- The face of the child when brought was covered with a purulent mass of scabs, and the child would scream with pain when any light was allowed to come to her eyes. She insisted on having a sunbonnet drawn closely over the face, shading the eyes. The eyes were firmly closed, and upon opening the lids I found the eyeballs turned up under the lids away from the light, and I was obliged to use lid retractors in order to get a view of the cornex. When I was able to see them, I found numerous papules upon the cornea. There was also pemphigus or watery blisters of the face, scalp and feet, as well as other parts of the body. I had a photograph taken of the child under chloroform, which shows a mass of scabs over the face. (The etching does not show as well as the photograph.) I commenced the use of methyl-violet in fluid form, 1 to 1,000 , dropped into 
the eyes, and on gauze as a mask over the face. The $[$ was discharged cured. In this case I purposely mask was left on until the following day, when the avoided using any other medicaments, thus relying condition of the face was already improved, and the wholly upon the methyl-violet, wishing to give it a child was able to open the left eye. On account of fair test. Now I do not claim that a cure in this case the cloth adhering to the sore surface, pomade of the might not have been brought about by other remedies; same strength of methyl-violet was substituted, and

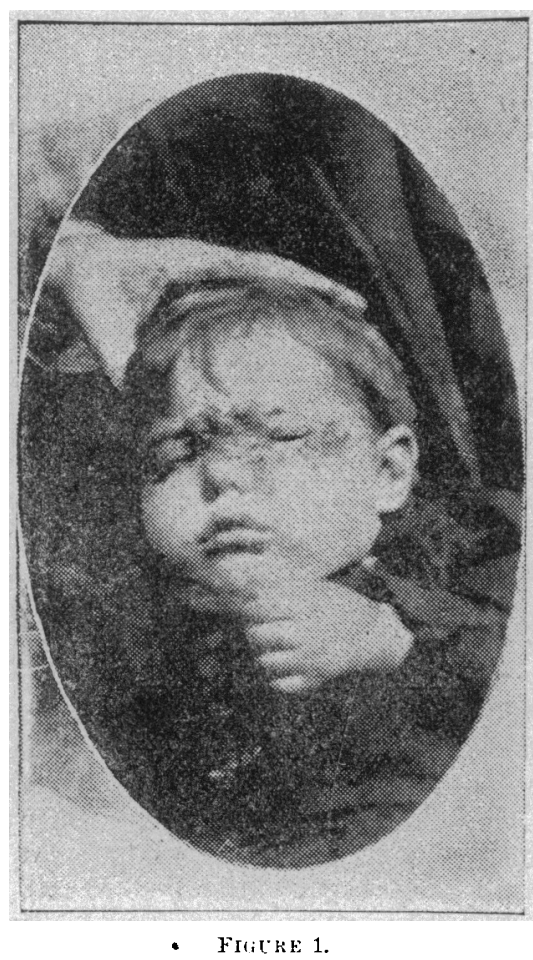

also put into the eyes. On the third or fourth day the child began to pull the bandage off the eyes, and look about with both eyes open, a thing she had not been able to do for several months. In less than a week from the time the methyl-violet was first used, both eyes would tolerate light, and we had little trouble in getting a good view of the cornex, which were rapidly clearing. On the ninth day a second photograph was taken, which shows the face clear from

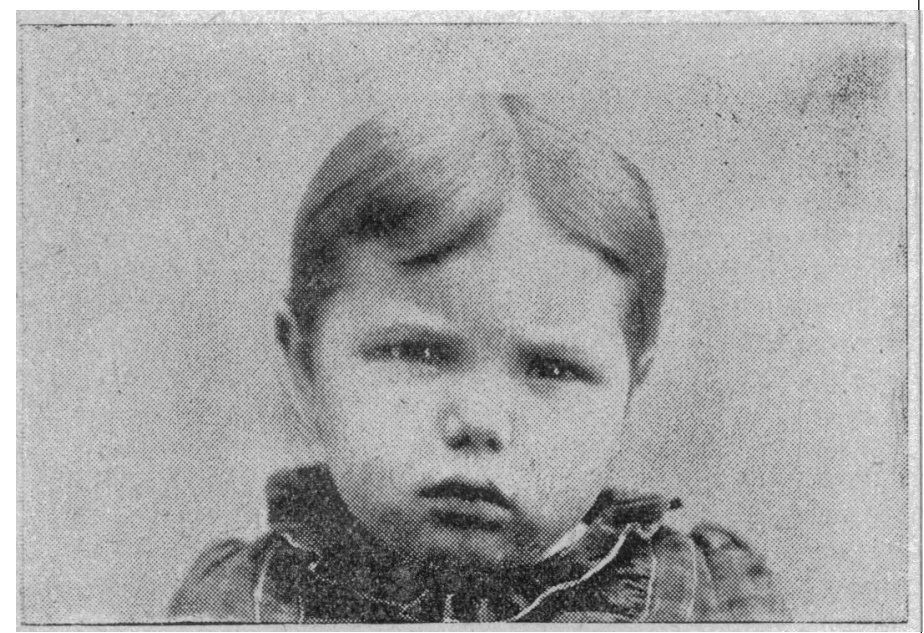

FigLrE 2.

sores and both eyes open, although, as the photograph indicates, when in bright light, as was necessary to get a good impression, there was some photophobia. In a shaded room she was able to hold the eyes wide open. In less than two weeks the patient but I do not believe it could have been accomplished in as short a time and with the apparent permanency, as up to the present writing there has been no recurrence of the disease (March 5, 1892). The eruption of the skin on other parts of the body was also treated by the same pomade of methyl-violet, and disappeared at about the same time as the corneal trouble. The child being evidently of a strumous cachexia, I gave her syrup of the iodide of iron, which I have no doubt assisted in the speedy cure.

Case 2.-Gust Nordland, age 24 years, farmer, Swede, came December 16, 1891, with the following

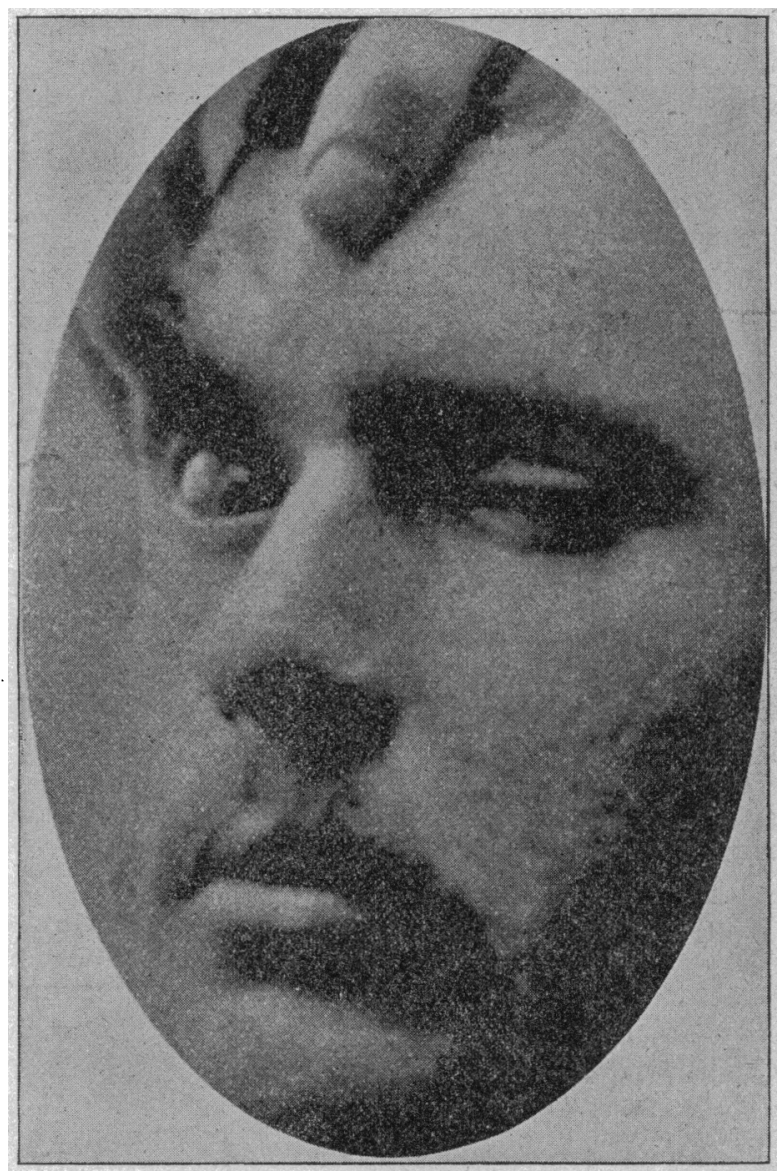

FIIIURE 3.

history: "Eight years ago I was struck over the right eye by a brush flying back from a man in front of me. We were in a boat and in the act of landing. I was holding the oars and could not protect myself. The old man in front caught the brush on his arm, and as he pulled away the brush flew back and struck my right eye. This immediately produced partial blindness, so I could not read with the eye, and the sight grew more dim each year. There was pain in the eye at the time, but it did not last long. No pain was felt afterwards until recently; now the eye aches all the time; last Sunday the pain was very severe." Sight has been gone for four years. Vision of right eye 0 ; vision of left eye $\frac{2}{2} \frac{\pi}{0}$. I find a tumor of the ball just back of the cornea at the superior and outer part, near the insertion of the oblique muscles, as 
large as a Lima bean. (Fig. 3.) The sclera over this bean. I diagnosed glioma, and advised enucleation. region is thin, showing the choroid through. The But the parents wished me to save the ball, if possigrowth or tumor, he says, has only been coming two ble without damage to the other eye. I insisted that months, and is now growing fast, increasing every there was danger of sympathetic ophthalmia of the day-probably sarcoma. December 17 , with hypo- fellow-eye, but no immediate danger. Not getting dermic syringe I injected the tumor with methyl- their consent to operate, I commenced the use of violet solution, 1 to 1,000 , gtts. $v$. There was a methyl-violet, 1 to 1,000 , dropped into the eye; this watery fluid escaped under the conjunctiva, pro- relieved pain and soreness of the eye. I prescribed ducing some chemosis. December 18, tumor re- a bottle of methyl-violet, to be taken home with them duced and pain gone. December 19 , no pain and less (in the country) and its use continued. The child tension. December 20, no pain, methyl-violet 1 to has been back to me several times since, and there 1,000 dropped in the eye once a day; this treat- has been no pain or soreness since the use of methylment was contimued for one week from the time of violet, and at the last visit the tumor seemed to be first injection. Then a fresh solution of 1 to 1,000 , smaller.

gtts. v, was injected into the vitreous chamber. The injection created some soreness of the ball, but no pain followed either injection. Care was taken that the needle used for the injection was sharp, the instrument aseptic and the fluid fresh. December 26, methyl-violet pomade was applied instead of fluid. Some pain followed this application. The fluid was resumed, 1 to $3 \mathrm{gtts}$. dropped in to the eye each day. Since then up to the present date there has been no pain or soreness; the eye feels comfortable, and the patient says it does not seem so large under the lid; tension is reduced to the normal. The ciliary injection, which was quite prominent when first examined, is nearly gone, and the tumor is certainly one-third smaller than at the first examination. At the last examination I noticed a slight retinal reflex of this eye, showing that the turbid vitreous was clearing; and the patient mentioned that he was now able to discern objects passed before the eye, something he had not been able to do before for several years. The appended letter shows the permanency of the good effect of the treatment:

IINDSBURY, KAx., January 27, 1892.

Dr. F. B. Tiffany, Kaxsas City, Mo.

Dear sir:-As the tumor of $m y$ eye is about the same as it was when I left Kansas City, I thought about writing to you for advice. Do you think it would be advisable to inject any more medicine? Do you think it would reduce the tumor by injecting any more? If so, please let me know by return mail, because I can go down with a carload of cattle that is going to be shipped from this place next week so it will cost me nothing to go down if I know it in time I have had no pain whatever in the eye since I came home. Respectfully yours, Gust Nordiand.

The first injection was made the 17 th of December, 1891 , and the second the 23d of December, 1891.

As the eye was quiet and evidently improving, I have not yet made the third injection, and up to the present writing (March 5) the eye still continues to improve.

Case 3.-M. Q., age 6 years, Quick City, Mo., came August 6, 1891. History as obtained from the father: About four weeks ago, the child stuck a table fork in his left eye, at the lower and inner third of the eye (ciliary margin of the iris).

Diagnosis.- Luxation and traumatic cataract of the lens. Vision, count fingers. This patient was brought during my absence from the city. My assistant, Dr. Merriman, made the above diagnosis. The parents then took the child to another oculist, who diagnosed suppuration of globe, and advised immediate removal of the eyeball. Some days later the child was brought back to my office, when an examination revealed a bright fleshy-looking body rising from the inferior ciliary region, with blood-vessels unting over it. The body was as large as a Lima drug.

Since methyl-violet has such an extraordinary penetrability, and canses. little or no irritability if used in the strength of 1 to 1,000 , and has for its predilection the nuclei of cells and bacilli, it seems especially indicated in deep-seated affections of the eye, especially those of the uveal tract.

\section{A PROPER SUBJECT FOR PUBLIC HEALTH.} BY E. CHENERY, M.D.

As I have been in dispensary work, I have been surprised at the prevalence of the itch, particularly among the Italians, and others of the lower foreign people who crowd together in uncleanliness, and then go through the community hawking their trinkets. Repeatedly I have seen persons covered from head to foot with this infectious disease, and on inquiry found that they were peddlars, going from house to house with cloth and other articles, which the people handle. Further inquiries have elicited the fact that they have had the eruption several years, and that others of the same dens are in a like condition. Now it is almost useless for a private or dispensary physician to attempt to eradicate the disease, even from one of them, to say nothing of exterminating the pest from the mass of filthy rags which they wear or amid which they sleep. Such dens of infection are far more worthy of public attention than many subjects of less practical importance. I have wished I could send word to the Board of Health, and have such people and such quarters taken into vigorous hands. As it is, I am afraid that our city board has reversed the old adage-attending to the dollars and leaving the cents to take care of themselves. Forty years ago a teacher of skin diseases came to the office of $\mathrm{my}$ preceptor, who had the oversight of large dispensary work at the north end, desiring that we would let him know of any case of scabies, for he said it was one of the rarest diseases in the city. According to my experience in that part of the city, he could not say that to-day. Boston may be an exception to other cities.

Electric Baths for the Treatmext of Syphilis. -At the General Hospital of Viemna iI. Kronfeld has found that the employment of electric baths causes a more complete and efficacious absorption of mercury than other methods of administering the drug. Nore mercury is eliminated in the urine; no. albuminuria is caused; polyuria is rare. The patients are stated to be cured in from two to four weeks after having taken from ten to twenty-five baths. Symptoms of mercurial poisoning must be looked out for in this as in other modes of using the 